\title{
Endogenous Skill Formation: Labor Market Integration by an Immigration
}

Titas Kumar Bandopadhyay

Bagnan College, West Bangal, India

Sarbajit Chaudhuri

University of Calcutta, Kolkata, India

\begin{abstract}
The paper fabricates endogenous skill formation in a two-sector general equilibrium model where the unemployment of the skilled workers is caused by efficiency wage. The paper also examines the effects of the immigration of unskilled labor, the emigration of skilled labor, and the inflow of foreign capital on unemployment, skilled-unskilled wage inequality, and the level of skill formation in each unskilled working family. We find that the immigration of unskilled labor raises both the rate and level of unemployment of the skilled labor and lowers both the relative skilled-unskilled wage inequality and the level of skill formation in each unskilled working family under certain conditions. However, the emigration of skilled labor or the inflow of foreign capital gives opposite results.
\end{abstract}

JEL Classifications: F13, J41, J64, O15

Key Words: Skill Formation, Wage Inequality, Unemployment, Skilled Labor

\footnotetext{
* Corresponding Author: Titas Kumar Bandopadhyay; Department of Economics, Bagnan College, 24/1 B.B.Halder Lane, Shibpur, Howrah-711102, West Bengal, India, Tel: +974 8109161, E-mail: titasban1@yahoo.in.

Co-Author: Sarbajit Chaudhuri; Department of Economics, University of Calcutta, 23 Dr. P.N. Guha Road, Belgharia, Kolkata 700083, India, Tel: +91 33 25575082, Fax: +91 33 28441490, E-mail: sarbajitch@yahoo.com.

Acknowledgements: The authors are indebted to an anonymous referee of his/her useful and interesting comments on an earlier version of the paper. However, the usual disclaimer applies. 


\section{Introduction}

Empirical studies show that the informal sector has been growing in the developing countries in the post reform period. However, the expanding informal sector has not been able to absorb the huge number of retrenched workers from the formal sector. As a result, the level of unemployment has been rising in many developing economies. The existence of unemployment may be explained in terms of efficiency wage theories. One version of efficiency wage theory is based on the work of Shapiro and Stiglitz (1984) where the efficiency of a worker is positively related to both the wage rate and the unemployment rate.

The liberalized economic policies have affected the welfare of the informal sector workers. Empirical studies of Khan (1998) and Tendulkar et al. (1996) point out the deterioration of the informal sector's wage earnings in India in the post reform period. Leite et al. (2006) have shown a significant decrease in average real wage for the informal sector workers in South Africa during 2000 2004.

The vast theoretical literature on the informal sector has not adequately addressed this issue. An important exception is Marjit (2003) who has shown that trade liberalization may raise the informal sector wage rate under some reasonable conditions and the positive effects on the informal wage would be strong if capital is mobile between formal and informal sectors.

Another important effect of economic reform is on the skilled-unskilled wage inequality in the developing economies. Empirical studies strongly suggest that the skilled - unskilled wage gap has increased in many developing economies in the post reform period. The studies of Robbins (1994 a, b; 1995 a, b; 1996 a, b) and Wood (1997) have shown that such wage inequality has downward trends in the East Asian countries, while in the Latin American countries like Mexico, Chile, Costa Rica, and Columbia it has increased in the post reform period. The study of Khan (1998) and Tendulkar et al. (1996) have also found the increased wage inequality in many developing economies. The empirical literature have identified three factors that are mainly responsible for the growing wage gap in the Latin American countries: removal of tariff from the unskilled labor intensive sector, growth of foreign direct investment, and decline in the union strength of unskilled workers.

Theoretically, the falling wage gap in the post reform period has been explained in the work of Feenstra and Hanson (1996), Marjit et al. (2000), Marjit et al. (2004), Marjit and Acharyya (2003), Chaudhuri and Yabuuchi (2007), and Yabuuchi and Chaudhuri (2007). Feenstra and Hanson (1996) have shown that an-inflow of foreign capital has led to the increased production of skilled intensive commodities in Mexico, thereby causing a falling demand for unskilled labor. Marjit et al. (2004) have shown that the nature of capital mobility between the formal and the informal sectors, the diverse trade pattern, and the market fragmentation in the world trade may adversely affect the skilled-unskilled wage gap in many developing economies.

Empirically, we also find the large scale emigration of skilled workers from the developing 
countries and this is expected to produce significant effects on unemployment, wage inequality, and skill formation. However, researchers have paid very little attention to this aspect. Exceptions are the papers of Marjit and Kar (2005), Beladi et al. (2008), and Chaudhuri (2008). Marjit and Kar (2005) have shown that emigration of unskilled workers worsens the wage inequality if the distributive share of the intersectorally mobile factor of the skilled sector is greater than that of the unskilled sector. Beladi et al. (2008) have examined the impact of international mobility of different factors of production on the relative wage inequality. However, the unemployment of the skilled labor and endogenous skill formation have not been taken care of in their models. Chaudhuri (2008) has shown that an emigration of skilled labor and an inflow of foreign capital may reduce wage inequality and unemployment if the low-skill urban sector is capital intensive. However, this paper has not considered endogenous skill formation.

The present paper develops a two sector general equilibrium model by incorporating efficiency wage and endogenous skill formation. Two types of labor are considered here: skilled and unskilled labor. The process of skill formation is generated on the part of the unskilled working families who determine the supply of unskilled workers on the basis of intertemporal utility maximization. The skilled workers get efficiency wage that causes unemployment in this model. Our theoretical analysis gives some interesting results. For instance, the immigration of unskilled labor raises the level and the rate of unemployment of the skilled labor and lowers the skilled-unskilled wage inequality and the level of skill formation in each unskilled working family. Meanwhile, the emigration of skilled labor or the inflow of foreign capital gives the opposite results.

\section{The Model}

We consider a small open economy consisting of $\bar{L}$ and $\bar{S}$ numbers of unskilled and skilled working families, respectively. In each working family, both skilled and unskilled, there are $N$ numbers of members. There are provisions for skill formation on the part of the unskilled workers. Each unskilled working family sends $L$ number of members for skill formation while the remaining $(N-L)$ members work as unskilled labor in Period 1. In Period 2, $L$ members become skilled labor while the remaining $(N-L)$ members continue to work as unskilled labor. We assume that there is a separate capitalist class who are the owners of capital and they do not supply any labor. On the other hand, skill formation on the part of skilled family members does not arise.

Our small open economy consists of two sectors: low-skill informal sector ${ }^{1}$ (Sector 1) and

\footnotetext{
'The unskilled labor market in a developing economy is imperfect and there is formal-informal sector segmentation. In the formal sector unskilled workers are organized and receive a higher unionized wage than what their counterparts receive in the informal sector of the economy. The unskilled workers who are unable to get employment in the formal sector are automatically absorbed in the informal
} 
high-skill sector (Sector 2). Sector 1 produces an agricultural commodity, $X_{1}$, using unskilled labour $(L)$ and capital $(K)$. Sector 2 produces a high-skill commodity, $X_{2}$, with the help of skilled labor $(S)$ and capital. Thus, unskilled labor is specific to Sector 1 while skilled labor is a specific input in Sector 2. However, capital is perfectly mobile between the two sectors. Skilled workers in Sector 2 receive the efficiency wage and this gives rise to the unemployment of skilled labor in the economy. On the contrary, the unskilled wage $(W)$ is completely flexible to clear the unskilled labor market. Thus, there is no unemployment of unskilled labor in the economy. ${ }^{2}$ Capital is also fully utilized. The capital endowment of the economy consists of both domestic capital $\left(K_{D}\right)$ and foreign capital $\left(K_{F}\right)$ and these are perfect substitutes. Commodity prices, $P_{i} \mathrm{~s}$, are given by the small open economy assumption. Competitive markets, except the market for skilled labor, and CRS technologies with diminishing marginal productivities of input are assumed. Finally, Commodity 1 is taken to be numeraire.

The following notations are used in the model: $X_{1}=$ level of output produced in Sector 1; $X_{2}=$ level of output produced in Sector $2 ; a_{j i}=$ amount of the jth input required to produce one unit of the $i$ th commodity; $\beta=$ time discount factor; $L_{i}=$ level of employment in $i$ th sector; $P_{1}=1$ (commodity 1 is the numeraire); $P_{2}=$ world price of commodity $2 ; W=$ unskilled wage rate; $W_{S}=$ skilled wage rate; $W_{S}^{*}=$ expected skilled wage rate; $w_{g}=$ percentage rate of expected wage gain; $r=$ rate of return on capital; $L=$ level of skill formation in each unskilled working family; $\bar{S}=$ level of skilled workers; $l_{S}=$ supply of unskilled labor by each unskilled working family; $L_{S}=$ aggregate supply of unskilled labor in the economy; $U=$ rate of skilled unemployment; $h=$ efficiency of each skilled labor; $h_{1}, h_{2}=$ first partials of the efficiency function with respect to $W_{S}, U ; h_{11}, h_{12}=$ second partials with respect to $W_{S}, U ; \omega=$ unit cost of skilled labour; $\varepsilon_{1}=$ elasticity of $h\left(\right.$.) function with respect to $W_{S} ; \varepsilon_{2}=$ elasticity of $h($.) function with respect to $U ; \varepsilon_{11}=$ elasticity of $h_{1}($.$) with respect to W_{S} ; K=$ total stock of capital in the economy; $K_{D}=$ stock of domestic capital in the economy; $K_{F}=$ inflow of foreign capital in the economy; $\mu=$ level of skilled unemployment; ${ }^{\wedge}=$ proportional change; $C_{i}=$ level of family consumption in the $i$ th period; $V=$ level of utility enjoyed by each unskilled working family; $\theta_{j i}=$ distributive share of the $j$ th input in the $i$ th sector, $i=1,2 ; j=L, K, S ; \lambda_{j i}=$ proportion of the $j$ th input employed in the $i$ th sector, $i=1,2 ; j=L, K, S ; S_{j k}{ }^{i}=$ the degree of substitution between factors $j$ and $k$ in the $i$ th sector, $i=1,2$ with $S_{j k}{ }^{i}>0$ for $j \neq k$ and $S_{j j}{ }^{i}<0$; .

sector. We, however, do not include a low-skill formal sector in our model as its inclusion cannot affect our main results in a meaningful way.

2 In reality, the informal sector and open unemployment of unskilled labour coexist. This happens if the informal sector unskilled wage is also rigid in the downward direction. However, we do not consider unemployment of unskilled labour because in an economy the possibility of being unemployed also rises with increasing education and skills. In the case of India, NSSO surveys conducted over the years show that the unemployment rate among those educated above the secondary level was higher, in both rural and urban areas, than those with lesser educational attainments. The NSSO 61st Round report, Employment and Unemployment Situation in India 200405, attributes this to the fact that "the job seekers become gradually more and more choosers as their educational level increases." Serneels (2007) also has found that in Ethiopia unemployment is concentrated among relatively well-educated first time job seekers who come from the middle classes. 


\section{A. Household behavior of unskilled working families and Derivation of family supply function of unskilled labor}

The supply function of unskilled labor by each working family is determined from its intertemporal utility maximizing behavior. We consider a two period optimizing problem of the representative unskilled working family consisting of $N$ members. $L$ is the number of unskilled workers that go for skill formation and they earn zero income in Period 1. However, in Period 2 they earn the expected skilled wage $(1-U) W_{S}$ while $(N-L)$ number of unskilled workers earns the unskilled wage $W$ in both the periods. In the presence of positive return to skill formation, the expected skilled wage $(1-U) W_{S}$ is not at least less than $W$.

We assume that each unskilled working family cares only about lifetime family consumption. The utility is therefore a function of consumption levels in the two periods (1 and 2). For algebraic simplicity we assume a logarithmic utility function with unitary intertemporal elasticity of substitution.

$$
V=\log C_{1}+\beta \log C_{2}
$$

The first period's consumption $\left(C_{1}\right)$ consists of wage income of $(N-L)$ number of family members that do not go for skill formation. Thus,

$$
C_{1}=W(N-L)
$$

The second period's consumption $\left(C_{2}\right)$ can be thought of as the sum of expected skilled wage of $L$ members of the family who have been upgraded as skilled labor by that time and unskilled wage of $(N-L)$ members who worked in Period 1 as unskilled labor.

$$
C_{2}=W(N-L)+(1-U) W_{S} L
$$

We assume that the only cost of skill formation is the opportunity cost in terms of forgone unskilled wage income of $L$ members of the family. ${ }^{4}$

The unskilled working family maximizes the lifetime utility (Equation 1) with respect to $L$ and subject to Equations 2 and 3. Maximization gives the following first-order condition. ${ }^{5}$

$$
\beta\left[\frac{(1-U) W_{S}-W}{W(N-L)+(1-U) W_{S} L}\right]=\frac{1}{(N-L)}
$$

\footnotetext{
${ }^{3}$ This is because otherwise no one would be interested in skill formation.

${ }^{4}$ One can incorporate direct costs without affecting the qualitative results of the model.

${ }^{5}$ The second-order condition of maximization is automatically satisfied as $\left(\frac{d^{2} V}{d L^{2}}\right)=-\frac{(1-\beta)}{\beta(N-L)^{2}}<0,(\because 0<\beta<1)$.
} 
Upon solving Equation 4, the number of members sent to skill formation from each family is found to be as follows.

$$
L=\frac{N \beta(1-U) W_{S}}{(1+\beta)\left[(1-U) W_{S}-W\right]}-\frac{W N}{\left[(1-U) W_{S}-W\right]}
$$

The supply function of unskilled labor by each family is given as

$$
l_{S}=(N-L)=\frac{N(1-U) W_{S}}{(1+\beta)\left[(1-U) W_{S}-W\right]}
$$

From Equation (6) it can be checked that the family supply of unskilled labor is a positive function of the unskilled wage, $W$, and the skilled unemployment rate, $U$, while it is a decreasing function of the skilled wage, $W_{S}$.

As there are $\bar{L}$ number of unskilled working families, the aggregate unskilled labor supply function in the economy, denoted $L_{S}$, is given by

$$
L_{S}=\frac{\bar{L} N(1-U) W_{S}}{(1+\beta)\left[(1-U) W_{S}-W\right]}
$$

\section{B. The General Equilibrium Analysis}

The efficiency function of each skilled labor is given by

$h=h\left(W_{S}, U\right)$ with $h_{1}, h_{2}>0 ; h_{11}<0 ; h_{12}=0$

Each firm in Sector 2 minimizes its unit cost of skilled labor, $\omega$, where

$$
\omega=\frac{W_{S}}{h(.)}
$$

The first-order condition of minimization of $\omega$ is

$$
h(.)=W_{s} h_{1}
$$

\footnotetext{
${ }^{6}$ In other words, the supply of unskilled labour by each family is a decreasing function of the expected skilled wage $W_{S}^{*}\left(=(1-U) W_{S}\right)$.
} 
or $\varepsilon_{1}=\left(\frac{\partial h}{\partial W_{S}}\right)\left(\frac{W_{S}}{h}\right)=1$

This is the well-known Solow condition in the efficiency wage literature. The usual priceunit cost equality conditions relating to the two sectors are as follows:

$$
\begin{aligned}
& W a_{L 1}+r a_{K 1}=1 \\
& \frac{W_{S}}{h} a_{S 2}+r a_{K 2}=P_{2}
\end{aligned}
$$

Complete utilization of unskilled labor and capital imply the three following equations, respectively.

$$
\begin{aligned}
& a_{L 1} X_{1}=\frac{\bar{L} N(1-U) W_{S}}{(1+\beta)\left[(1-U) W_{S}-W\right]} \\
& a_{K 1} X_{1}+a_{K 2} X_{2}=K_{D}+K_{F}=K
\end{aligned}
$$

The endowment of skilled labor is given by

$$
a_{S 2} X_{2}=(1-U) h(\cdot) \bar{S}
$$

The general equilibrium system comprises of eight equations, (8) (14), and the same number of endogenous variables; namely, $W, W_{S}, h, r, X_{1}, X_{2}$ and $U$. Using Equation (12) and (14), Equation (13) can be rewritten as follows:

$$
\left(\frac{a_{K 1}}{a_{L 1}}\right)\left[\frac{\bar{L} N(1-U) W_{S}}{(1+\beta)\left\{(1-U) W_{S}-W\right\}}\right]+\left(\frac{a_{K 2}}{a_{S 2}}\right)(1-U) h(\cdot) \bar{S}=K_{D}+K_{F}=K
$$

From Equations (8) and (9) we write

$$
h_{1} W_{S}=h\left(W_{S}, U\right)
$$

Now solving Equations (10), (11), (13.1), and (15) simultaneously we can obtain the equilibrium values of $W, W_{S}, r$ and $U$. Afterwards, $h$ is obtained from Equation (8). Finally, $X_{1}$ and $X_{2}$ are found from Equation (12) and (14), respectively.

All skilled workers are not employed. The probability for a skilled worker of getting a job is ( $1-U)$, where $U$ is the rate of skilled unemployment. Hence, the expected skilled wage, denoted 
$W_{S}^{*}$, is given by

$$
W_{S}^{*}=(1-U) W_{S}
$$

The percentage rate of expected wage gain is

$$
w_{g}=\frac{W_{S}}{W_{S}^{*}}-1>0
$$

The relative skilled-unskilled wage inequality is measured as $\left(W_{S}^{*}-\hat{W}\right)$.

\section{Comparative Statics}

We are now going to find out the effects of an increase in $\bar{L}$ and $K$ and a decrease in $\bar{S}$ on unemployment of skilled labor, on relative skilled-unskilled wage inequality, and on the level of skill formation in each unskilled working family $(L)$.

Totally differentiating Equations (4), (10), (11), (13.1), and (15), and using envelope conditions, and solving by Cramer's rule we get the following propositions. ${ }^{7}$

Proposition 1: An immigration of unskilled workers raises both the rate and level of unemployment of the skilled labor. This policy lowers the relative skilled-unskilled wage inequality if $\left(\theta_{L 1} \theta_{K 2}+\theta_{K 1} \theta_{S 2} \varepsilon_{11}\right) \geq 0$. Further, the immigration of unskilled workers lowers the level of skill formation in each unskilled family if $\left(W_{S}^{*} \theta_{L 1} \theta_{K 2}+\theta_{K 1} \theta_{S 2} \delta \varepsilon_{11}\right) \geq 0$.

We may explain Proposition 1 as follows. If there occurs an immigration of unskilled labor from the neighboring countries, the number of unskilled working families, $\bar{L}$, rises. As the production structure is indecomposable, all factor prices and other endogenous variables are affected. An increase in the number of the unskilled family lowers unskilled wage rate, $W$, leading to an expansion of Sector 1. As Sector 1 expands, capital moves from Sector 2 to Sector 1 , leading to a contraction of Sector 2. Thus, the demand for skilled labor falls and so, the skilled wage rate, $W_{S}$, falls. The rate and the level of unemployment of the skilled labor rise.

The relative skilled-unskilled wage inequality falls if $\left(\theta_{L 1} \theta_{K 2}+\theta_{K 1} \theta_{S 2} \varepsilon_{11}\right) \geq 0$. Again, with the immigration of unskilled labor, expected skilled wage rate, $W_{S}^{*}$, falls. Now, the unskilled working family will send less labor for skill formation and as a result, the level of skill forma-

See Appendix 1 and Appendix 2 for detailed derivations. 
tion in each of the unskilled working family decreases under the following condition:

$$
\left(W_{S}^{*} \theta_{L 1} \theta_{K 2}+\theta_{K 1} \theta_{S 2} \delta \varepsilon_{11}\right) \geq 0
$$

Proposition 2: An emigration of skilled labor lowers both the level and the rate of unemployment of the skilled labor, raises both the relative skilled-unskilled wage inequality and the level of skill formation under the same sufficient conditions as required to get Proposition 1.

Proposition 2 may be explained as follows. As the level of skilled workers falls, $W_{S}$ rises and Sector 2 contracts. The rate and the level of unemployment of skilled labor fall. Capital moves from Sector 2 to Sector 1. Thus, Sector 1 expands and the demand for unskilled labor rises. At the same time as the expected wage rate rises, more labor will go for skill formation and thus the effective supply of unskilled labor falls and this raises $W$. Now, if Sector 2 is capital intensive in the sense that $\left(\theta_{L 1} \theta_{K 2}+\theta_{K 1} \theta_{S 2} \varepsilon_{11}\right), W_{S}^{*}$ rises more than $W$. This raises the relative skilled-unskilled wage inequality. Again, the capital intensity condition that $\left(W_{S}^{*} \theta_{L 1} \theta_{K 2}\right.$ $\left.+\theta_{K 1} \theta_{S 2} \delta \varepsilon_{11}\right) \geq 0$ also raises the level of skill formation in each unskilled working family.

Proposition 3: An inflow of foreign capital lowers the rate and level of unemployment of the skilled labor, raises the relative skilled-unskilled wage inequality and the level of skill formation under the same sufficient conditions as required to get Propositions 1 and 2.

We can explain Proposition 3 as follows. An inflow of foreign capital leads to a fall in the return to capital, $r$. Following Rybczynski theorem, Sector 2 expands and Sector 1 contracts with the increase in foreign capital. The demand for skilled labor increases causing a fall in the rate and the level of unemployment of the skilled labor, given the endowment of the skilled labor. Here, both $W_{S}$ and $W$ increase with the inflow of foreign capital. Again, the expected skilled wage rate rises. If Sector 2 is capital intensive in the sense that $\left(\theta_{L 1} \theta_{K 2}+\theta_{K 1} \theta_{S 2} \varepsilon_{11}\right) \geq 0$, $W_{S}$ rises more than $W$. This raises the relative wage inequality. Further, the level of skill formation in each unskilled working family is likely to increase under the following condition: $\left(W_{S}^{*} \theta_{L 1} \theta_{K 2}+\theta_{K 1} \theta_{S 2} \delta \varepsilon_{11}\right) \geq 0$

\section{Concluding Remarks}

This paper introduces endogenous skill formation and unemployment of skilled labor in a two sector general equilibrium model where unemployment is caused due to the efficiency wage that the skilled workers receive. The process of skill formation is undertaken in the unskilled sector where each unskilled working family decides how many workers to send for skill formation on the basis of the intertemporal utility maximization. This gives birth to the supply of skilled labor.

Our analysis shows that the rate and level of unemployment of the skilled labor fall while 
the level of skill formation and the wage inequality rise unambiguously due to policies like inflow of foreign capital or emigration of skilled labor. On the other hand, an immigration of unskilled labor lowers wage inequality and the level of skill formation in the unskilled working family and raises the rate and the level of unemployment of the skilled labor. These results may provide a theoretical foundation for empirical findings regarding the behavior of macroeconomic variables like unemployment, wage inequality, and skill formation in the post reform period.

Received 8 May 2012, Revised 5 November 2012, Accepted 22 November 2012

\section{References}

Beladi, H. , Chaudhuri, S. , Yabuuchi, S. (2008) Can International Factor Mobility Reduce Wage Inequality in a Dual Economy?, Review of International Economics, 16, 893-903.

Chaudhuri, S. and Yabuuchi, S. (2007) Economic Liberalisation and Wage Inequality in the Presence of Labour Market Imperfectio, International Review of Economics and Finance, 16(4), 592-603.

Chaudhuri, S. (2008) Wage Inequality in a Dual Economy and International Mobility of Factors: Do Factor Intensities Always Matter?, Economic Modelling, Elsevier, 25(6), 1155-1164.

Feenstra, R.C., Hanson, G.H. (1997) Foreign Direct Investment and Relative Wages: Evidence from Mexico's Maquiladoras, Journal of International Economics, 42, 371-394.

Khan, A.R. (1998) The Impact of Globalisation in South Asia, in A.S. Bhalla (ed.), Globalisation, Growth and Marginalisation, Macmillan India Ltd, New Delhi.

Leite, P.G., McKinley, T. , Osorio, R.G. (2006) The Post -Apartheid Evolution of Earnings Inequality in South Africa, 1995-2004, Working Paper No. 32, International Poverty Centre, UNDP,Brazil.

Marjit, S. (2003) Economic Reform and Informal wage- A General Equilibrium Analysis, Journal of Development Economics, 72(1), 371-378.

Marjit, S., Acharyya, R. (2003) International Trade, Wage Inequality and the Developing Economy-A General Equilibrium Approach, Germany:Springer-Verlag.

Marjit, S., Beladi, H. and Chakraborty, A.(2004) Trade and Wage Inequality in Developing Countries, Economic Inquiry, 42(2), 295-303.

Marjit, S., Broll, U. and Sengupta, S. (2000) Trade and Wage- Gap in Poor Countries: The Role of the Informal Sector', in A. Bose et al. (eds.), Macroeconomics, Trade and Institutions: Essays in Honour of M.K.Rakshit, Oxford University Press, Kolkata.

Marjit, S. and Kar, S. (2005) Emigration and Wage Inequality, Economic Letters, 88, 141-145.

Robbins, D. (1994a) Malaysian Wage Structure and its Causes, Harvard Institute for International Development (HIID).

Robbins, D. (1994b) Phillipine Wage and Employment Structure 1978-1983, HIID. 
Robbins, D. (1995a) Earnings Dispersions in Chile after Trade Liberalisation, HIID.

Robbins, D. (1995b) Trade, Trade Liberalisation and Inequality in Latin America and East Asia: Synthesis of Seven Country Studies, HIID.

Robbins, D. (1996a) Stolper-Samuelson Lost in the Tropics-Trade liberalization and Wages in Columbia, HIID.

Robbins, D. (1996b) HOS Hits Facts: Facts Win: Evidence on Trade and Wages in Developing World, HIID.

Shapiro, S. , Stiglitz, J.E. (1984) Equilibrium Unemployment as a Worker Discipline Device, 74(3), 433-444.

Tendulkar, S., Sundaram, D.K. and Jain, L R. (1996) Macroeconomic Policies and Poverty in India 1966-67 to 1993-94, Manuscript. ILO, New Delhi.

Wood, A. (1997) Openness and Wage Inequality in Developing Countries: The Latin American Challenge to East Asian Conventional Wisdom, World Bank Research Observer, January.

Yabuuchi, S. , Chaudhuri, S. (2007) International Migration of Labour and Skilled-Unskilled Wage Inequality in a Develoiping Economy, Economic Modelling, 24(1), 128-137. 


\section{Appendices}

\section{Appendix 1: Derivations of some useful expressions}

Totally differentiating equations (10), (11), (13.1) and (15) and using envelope conditions we get

$$
\begin{aligned}
& \theta_{L 1} \hat{W}+\theta_{K 1} \hat{r}=0 \\
& \theta_{K 2} \hat{r}-\theta_{S 2} \varepsilon_{2} \hat{U}=\hat{P}_{2} \\
& A_{1} \hat{W}+A_{2} \hat{W}_{S}+A_{3} \hat{U}+A_{4} \hat{r}=B_{1} \hat{K}-B_{2} \hat{\bar{S}}-B_{3} \hat{\bar{L}} \\
& \varepsilon_{11} \hat{W}_{S}-\varepsilon_{2} \hat{U}=0
\end{aligned}
$$

The matrix form of these equations is:

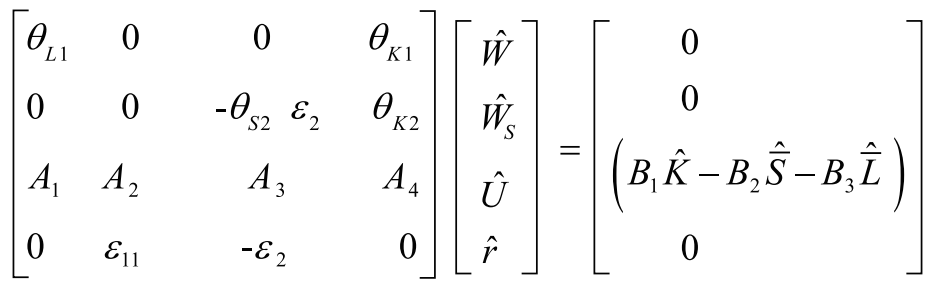

where

$$
\begin{aligned}
& A_{1}=\lambda_{K 1}\left[W-\left(S_{K K}^{1}+S_{L L}^{1}\right)\left\{(1-U) W_{S}-W\right\}\right](1-U)>0 \\
& A_{2}=\left[\lambda_{K 2}\left\{(1-U) W_{S}-W\right\}\left\{1-\left(S_{K K}^{2}+S_{S S}^{2}\right)\right\}-\lambda_{K 1} W\right](1-U)>0 \\
& A_{3}=\left[\lambda_{K 2}\left\{(1-U) W_{S}-W\right\} \frac{W_{S}^{*}}{W_{S}}\left(\varepsilon_{2}-w_{g}\right)+\lambda_{K 1} W U\right] \\
& A_{4}=\left[\lambda_{K 1}\left(S_{K K}^{1}+S_{L L}^{1}\right)+\lambda_{K 2}\left(S_{K K}^{2}+S_{S S}^{2}\right)\right]\left\{(1-U) W_{S}-W\right\}(1-U)>0 \\
& B_{1}=\left[\left\{(1-U) W_{S}-W\right\}(1-U)\right]>0 ; B_{2}=\left[\lambda_{K 2}\left\{(1-U) W_{S}-W\right\}(1-U)\right]>0 \\
& B_{3}=\left[\lambda_{K 1}\left\{(1-U) W_{S}-W\right\}(1-U)\right]>0 ; \varepsilon_{2}=\frac{h_{2} U}{h}>0 ;
\end{aligned}
$$




$$
\varepsilon_{11}=\left(\frac{\partial h_{1}}{\partial W_{S}} \cdot \frac{W_{S}}{h_{1}}\right)<0
$$

To simplify matters and derive some useful comparative static results under meaningful sufficient conditions let us now assume that $\varepsilon_{2}<w_{g}$. This implies that $A_{3}<0$.

Solving by Cramer's rule, the following expressions can be derived easily from (1.5):

$$
\begin{aligned}
& \hat{W}=-\left(\frac{1}{\Delta}\right) \theta_{K 1} \theta_{S 2} \varepsilon_{2} \varepsilon_{11}\left(B_{1} \hat{K}-B_{2} \hat{\bar{S}}-B_{3} \hat{\bar{L}}\right) \\
& \hat{W}_{S}=-\left(\frac{1}{\Delta}\right) \varepsilon_{2} \theta_{L 1} \theta_{K 2}\left(B_{1} \hat{K}-B_{2} \hat{\bar{S}}-B_{3} \hat{\bar{L}}\right) \\
& \hat{U}=\left(\frac{1}{\Delta}\right) \varepsilon_{11} \theta_{L 1} \theta_{K 2}\left(B_{1} \hat{K}-B_{2} \hat{\bar{S}}-B_{3} \hat{\bar{L}}\right)
\end{aligned}
$$

where $\Delta$ is the determinant of the coefficient matrix (1.5) and

$$
\begin{gathered}
\Delta=h\left[-\left\{A_{4} \theta_{L 1} \theta_{S 2} \varepsilon_{2}+\theta_{L 1} \theta_{K 2} A_{3}-A_{1} \theta_{K 1} \theta_{S 2} \varepsilon_{2}\right\}\right. \\
(-) \\
(-)
\end{gathered}
$$

The level of unemployment of skilled labour is

$$
\begin{aligned}
& u=U \bar{S} \\
& \therefore \hat{u}=\hat{U}+\hat{\bar{S}}
\end{aligned}
$$

The relative skilled-unskilled wage inequality is measured as: $\left(\hat{W}_{S}^{*}-\hat{W}\right)$, where $W_{S}^{*}=(1-U) W_{S}$ is the average (or expected) skilled wage.

$$
\therefore\left(\hat{W}_{s}^{*}-\hat{W}\right)=\hat{W}_{s}-w_{g} \hat{U}-\hat{W}
$$

Totally differentiating equation (14) and using $\hat{a}_{S 2}=S_{S S}^{2} \hat{W}_{S}+S_{K S}^{2} \hat{r}, S_{S S}^{2}+S_{K S}^{2}=0$ we get,

$$
\hat{X}_{2}=\left(1-S_{S S}^{2}\right) \hat{W}_{S}+S_{S S}^{2} \hat{r}+\hat{\bar{S}}+\left(\varepsilon_{2}-w_{g}\right) \hat{U}
$$

Totally differentiating equation (13) and using 


$$
\begin{aligned}
& \hat{a}_{K 1}=-S_{K K}^{1}(\hat{W}-\hat{r}), \hat{a}_{K 2}=-S_{K K}^{2}\left(\hat{W}_{S}-\hat{r}\right) \\
& \hat{X}_{1}=\left(\frac{1}{\lambda_{K 1}}\right) \hat{K}+S_{K K}^{1} \hat{W}+\frac{\lambda_{K 2}}{\lambda_{K 1}} \cdot S_{K K}^{2} \hat{W}_{S}-\left(S_{K K}^{1}+\frac{\lambda_{K 2}}{\lambda_{K 1}} \cdot S_{K K}^{2}\right) \hat{r}-\frac{\lambda_{K 2}}{\lambda_{K 1}} \hat{X}_{2}
\end{aligned}
$$

\section{Appendix 2: Effects a change in $\bar{L}$}

From (1.7)-(1.9) we get,

$$
\begin{aligned}
& \left(\frac{\hat{W}}{\hat{\bar{L}}}\right)=-\left(\frac{1}{\Delta}\right) \theta_{K 1} \theta_{S 2} \varepsilon_{2} B_{3} \varepsilon_{11}<0 \\
& \left(\frac{\hat{W}}{\hat{\bar{L}}}\right)=\left(\frac{1}{\Delta}\right) \theta_{L 1} \theta_{K 2} \varepsilon_{2} B_{3}<0 \\
& \left(\frac{\hat{U}}{\hat{\bar{L}}}\right)=\left(\frac{1}{\Delta}\right) \varepsilon_{11} B_{3} \theta_{L 1} \theta_{K 2}>0
\end{aligned}
$$

Using (2.1) into (1.11) we get,

$$
\left(\frac{\hat{u}}{\hat{\bar{L}}}\right)=\left(\frac{\hat{U}}{\hat{\hat{L}}}\right)>0
$$

Using (2.1) into (1.13) and (1.14) we get,

$$
\begin{aligned}
& \frac{\hat{X}_{2}}{\hat{\bar{L}}}=\left(1-S_{S S}^{2}\right)\left(\frac{\hat{W}_{S}}{\hat{\bar{L}}}\right)+S_{S S}^{2}\left(\frac{\hat{r}}{\hat{\bar{L}}}\right)+\left(\varepsilon_{2}-w_{g}\right)\left(\frac{\hat{U}}{\hat{\bar{L}}}\right)<0, \\
& (+) \quad(-) \quad(-)(+) \quad(-) \quad(+) \\
& \frac{\hat{X}_{1}}{\hat{\bar{L}}}=S_{K K}^{1}\left(\frac{\hat{W}}{\hat{\bar{L}}}\right)+\frac{\lambda_{K 2}}{\lambda_{K 1}} \cdot S_{K K}^{2}\left(\frac{\hat{W}_{S}}{\hat{\bar{L}}}\right)-\left(S_{K K}^{1}+\frac{\lambda_{K 2}}{\lambda_{K 1}} \cdot S_{K K}^{2}\right)\left(\frac{\hat{r}}{\hat{\hat{L}}}\right)-\frac{\lambda_{K 2}}{\lambda_{K 1}}\left(\frac{\hat{X}_{2}}{\hat{\bar{L}}}\right)>0, \\
& (-)(-) \\
& (-) \quad(-) \quad(-) \\
& (-) \quad(+)
\end{aligned}
$$

Using (2.1) into (1.12) we get, 


$$
\begin{aligned}
& \frac{\left(W_{S}^{*}-\hat{W}\right)}{\hat{\bar{L}}}=\left(\frac{B}{\Delta}\right)\left[\left(\theta_{L 1} \theta_{K 2}+\theta_{K 1} \theta_{S 2} \varepsilon_{11}\right) \varepsilon_{2}-w_{g} \theta_{L 1} \theta_{K 2} \varepsilon_{11}\right]<0 \\
& \quad(-) \\
& \text { if }\left(\theta_{L 1} \theta_{K 2}+\theta_{K 1} \theta_{S 2} \varepsilon_{11}\right) \geq 0
\end{aligned}
$$

Totally differentiating equation (5) with respect to $\bar{L}$ and using equations (2.1), (4) one gets,

$$
\left(\frac{\hat{L}}{\hat{\bar{L}}}\right)=\frac{M B_{3}}{\Delta}\left[\left(W_{S}^{*} \theta_{L 1} \theta_{K 2}+\theta_{K 1} \theta_{S 2} \delta \varepsilon_{11}\right) \varepsilon_{2}-W_{S} U \theta_{L 1} \theta_{K 2} \varepsilon_{11}\right]<0
$$

if $\left(W_{S}^{*} \theta_{L 1} \theta_{K 2}+\theta_{K 1} \theta_{S 2} \delta \varepsilon_{11}\right) \geq 0$

where $M=\left[\frac{N \beta-L(1+\beta)}{L(1+\beta)\left\{(1-U) W_{S}-W\right\}}\right]>0$,

$\delta=\left[\frac{\beta N-L(1+\beta)+N}{\beta N-L(1+\beta)}\right] W>1$

\section{Appendix 3: Effects of a change in $\bar{S}$}

$$
\begin{aligned}
& \left(\frac{\hat{W}}{\hat{\hat{S}}}\right)=-\left(\frac{1}{\Delta}\right) \theta_{K 1} \theta_{S 2} \varepsilon_{2} B_{2} \varepsilon_{11}<0 \\
& \left(\frac{\hat{W}_{S}}{\hat{\hat{S}}}\right)=\left(\frac{1}{\Delta}\right) \theta_{L 1} \theta_{K 2} \varepsilon_{2} B_{2} \quad<0 \\
& \left(\frac{\hat{U}}{\hat{\bar{S}}}\right)=\left(\frac{1}{\Delta}\right) \varepsilon_{11} B_{2} \theta_{L 1} \theta_{K 2} \quad>0 \\
& \left(\frac{\hat{r}}{\hat{S}}\right)=\left(\frac{1}{\Delta}\right) \varepsilon_{11} \varepsilon_{2} B_{2} \theta_{L 1} \theta_{S 2} \quad>0 \\
& \left(\frac{\hat{u}}{\hat{\hat{S}}}\right)=\left(\frac{\hat{U}}{\hat{\hat{S}}}\right)+1>0
\end{aligned}
$$

Now, from (1.13), (1.14) and (3.1) we get, 


$$
\begin{array}{r}
\left(\frac{\hat{X}_{2}}{\hat{\bar{S}}}\right)=\left(1-S_{S S}^{2}\right)\left(\frac{\hat{W}_{S}}{\hat{\bar{S}}}\right)+S_{S S}^{2}\left(\frac{\hat{r}}{\hat{\hat{S}}}\right)+1+\left(\varepsilon_{2}-w_{g}\right)\left(\frac{\hat{U}}{\hat{\bar{S}}}\right) \\
(+) \quad(-)(+) \quad(+)
\end{array}
$$

Since Sector 2 uses skilled labour, an emigration of skilled labour leads to a fall in the production of commodity 2 . This implies that $\left(\frac{\hat{X}_{2}}{\hat{\bar{S}}}\right)<0$

$$
\begin{aligned}
\left(\frac{\hat{X}_{1}}{\hat{\bar{S}}}\right)= & S_{K K}^{1}\left(\frac{\hat{W}}{\hat{\hat{S}}}\right)+\frac{\lambda_{K 2}}{\lambda_{K 1}} \cdot S_{K K}^{2}\left(\frac{\hat{W}_{S}}{\hat{\bar{S}}}\right)-\left(S_{K K}^{1}+\frac{\lambda_{K 2}}{\lambda_{K 1}} \cdot S_{K K}^{2}\right)\left(\frac{\hat{r}}{\hat{\hat{S}}}\right)-\frac{\lambda_{K 2}}{\lambda_{K 1}}\left(\frac{\hat{X}_{2}}{\hat{\bar{S}}}\right) \\
& (-)(-) \quad(-)(-) \quad(-)
\end{aligned}
$$

Using (3.1) into (1.12) we get,

$$
\begin{aligned}
& \frac{\left(W_{S}^{*}-\hat{W}\right)}{\hat{S}}=\left(\frac{B_{2}}{\Delta}\right)\left[\left\{\theta_{L 1} \theta_{K 2}+\theta_{K 1} \theta_{S 2} \varepsilon_{11}\right\} \varepsilon_{2}-w_{g} \varepsilon_{11} \theta_{L 1} \theta_{K 2}\right]<0, \\
& (-) \\
& \text { if }\left(\begin{array}{lll}
\theta_{L 1} \theta_{K 2}+\theta_{K 1} & \theta_{S 2} & \varepsilon_{11}
\end{array}\right) \geq 0
\end{aligned}
$$

Totally differentiating Equation (5) with respect to $\bar{S}$ and using (3.1), (4) one gets,

$$
\begin{aligned}
& \left(\frac{\hat{L}}{\hat{\bar{S}}}\right)=\left(\frac{M B_{2} \varepsilon_{2}}{\Delta}\right)\left[\left(W_{S}^{*} \theta_{L 1} \theta_{K 2}+\theta_{K 1} \theta_{S 2} \delta \varepsilon_{11}\right)-\theta_{L 1} \theta_{K 2} W_{S} U \varepsilon_{11}\right]<0, \\
& (-) \\
& \text { if }\left(W_{S}^{*} \theta_{L 1} \theta_{K 2}+\theta_{K 1} \theta_{S 2} \delta \varepsilon_{11}\right) \geq 0
\end{aligned}
$$




\section{Appendix 4: Effects of a change in $K_{F}$ :}

$$
\begin{aligned}
& \left(\frac{\hat{W}}{\hat{K}_{F}}\right)=\left(\frac{1}{\Delta}\right) \theta_{K 1} \theta_{S 2} \varepsilon_{2} B_{1} \varepsilon_{11}>0 \\
& \left(\frac{\hat{W}_{S}}{\hat{K}_{F}}\right)=-\left(\frac{1}{\Delta}\right) \theta_{L 1} \theta_{K 2} \varepsilon_{2} B_{1}>0 \\
& \left(\frac{\hat{U}}{\hat{K}_{F}}\right)=-\left(\frac{1}{\Delta}\right) \varepsilon_{11} B_{1} \theta_{L 1} \theta_{K 2}<0 \\
& \left(\frac{\hat{r}}{\hat{K}_{F}}\right)=-\left(\frac{1}{\Delta}\right) \varepsilon_{11} \varepsilon_{2} B_{1} \theta_{L 1} \theta_{S 2}<0 \\
& \left(\begin{array}{c}
\hat{u} \\
\hat{K}_{F}
\end{array}\right)=\left(\frac{\hat{U}}{\hat{K}_{F}}\right)<0
\end{aligned}
$$

Now, from (2.6) and (2.7) we get,

$$
\begin{aligned}
&\left(\frac{\hat{X}_{2}}{\hat{K}_{F}}\right)=\left(1-S_{S S}^{2}\right)\left(\frac{\hat{W}_{S}}{\hat{K}_{F}}\right)+S_{S S}^{2}\left(\frac{\hat{r}}{\hat{K}_{F}}\right)+\left(\varepsilon_{2}-w_{g}\right)\left(\frac{\hat{U}}{\hat{K}_{F}}\right)>0 \\
&(+) \quad(+) \quad(-)(-) \quad(-) \quad(-) \\
&\left(\frac{\hat{X}_{1}}{\hat{K}_{F}}\right)=\left(\frac{1}{\lambda_{K 1}}\right)+S_{K K}^{1}\left(\frac{\hat{W}}{\hat{K}_{F}}\right)+\frac{\lambda_{K 2}}{\lambda_{K 1}} \cdot S_{K K}^{2}\left(\frac{\hat{W}_{S}}{\hat{K}_{F}}\right)-\left(S_{K K}^{1}+\frac{\lambda_{K 2}}{\lambda_{K 1}} \cdot S_{K K}^{2}\right)\left(\frac{\hat{r}}{\hat{K}_{F}}\right)-\frac{\lambda_{K 2}}{\lambda_{K 1}}\left(\frac{\hat{X}_{2}}{\hat{K}_{F}}\right) \\
&(-)(+)(-)(+) \quad(-)
\end{aligned}
$$

Sector 2 expands capital moves from Sector 1 to Sector 2. Thus, Sector 1 contracts. This implies that

$$
\left(\frac{\hat{X}_{1}}{\hat{K}_{F}}\right)<0
$$

Now, 


$$
\begin{aligned}
& \frac{\left(\hat{W}_{S}^{*}-\hat{W}\right)}{\hat{K}_{F}}=-\underset{(-)}{\left(\frac{B_{1}}{\Delta}\right)\left[\left(\theta_{L 1} \theta_{K 2}+\theta_{K 1} \theta_{S 2} \varepsilon_{11}\right) \varepsilon_{2}-w_{g} \varepsilon_{11} \theta_{L 1} \theta_{K 2}\right]>0,} \\
& \operatorname{if}\left(\theta_{L 1} \theta_{K 2}+\theta_{K 1} \theta_{S 2} \varepsilon_{11}\right) \geq 0
\end{aligned}
$$

Totally differentiating equation (5) with respect to $K_{F}$ and using equations (4), (4.1) one gets,

$$
\begin{aligned}
& \left(\frac{\hat{L}}{\hat{K}_{F}}\right)=-\left(\frac{M B_{1}}{\Delta}\right)\left[\left(W_{S}^{*} \theta_{L 1} \theta_{K 2}+\theta_{K 1} \theta_{S 2} \delta \varepsilon_{11}\right) \varepsilon_{2}-\theta_{L 1} \theta_{K 2} W_{S} U \varepsilon_{11}\right]>0, \\
& (-) \\
& \operatorname{if}\left(W_{S}^{*} \theta_{L 1} \theta_{K 2}+\theta_{K 1} \theta_{S 2} \delta \varepsilon_{11}\right) \geq 0
\end{aligned}
$$

